\title{
Estimation of COVID-19 Period Prevalence and the Undiagnosed Population in Canadian Provinces: Model-Based Analysis
}

Abdullah Hamadeh ${ }^{1}$, PhD; Zeny Feng ${ }^{2}, \mathrm{PhD}$; Jessmyn Niergarth ${ }^{2}, \mathrm{PhD}$; William WL Wong ${ }^{1}, \mathrm{PhD}$

${ }^{1}$ School of Pharmacy, University of Waterloo, Kitchener, ON, Canada

${ }^{2}$ Department of Mathematics and Statistics, University of Guelph, Guelph, ON, Canada

\section{Corresponding Author:}

William WL Wong, PhD

School of Pharmacy

University of Waterloo

10 A Victoria Street $S$

Kitchener, ON, N2G1C5

Canada

Phone: 15198884567 ext 21323

Email:wwlwong@uwaterloo.ca

\section{Abstract}

Background: The development of a successful COVID-19 control strategy requires a thorough understanding of the trends in geographic and demographic distributions of disease burden. In terms of the estimation of the population prevalence, this includes the crucial process of unravelling the number of patients who remain undiagnosed.

Objective: This study estimates the period prevalence of COVID-19 between March 1, 2020, and November 30, 2020, and the proportion of the infected population that remained undiagnosed in the Canadian provinces of Quebec, Ontario, Alberta, and British Columbia.

Methods: A model-based mathematical framework based on a disease progression and transmission model was developed to estimate the historical prevalence of COVID-19 using provincial-level statistics reporting seroprevalence, diagnoses, and deaths resulting from COVID-19. The framework was applied to three different age cohorts $(<30 ; 30-69$; and $\geq 70$ years $)$ in each of the provinces studied.

Results: The estimates of COVID-19 period prevalence between March 1, 2020, and November 30, 2020, were 4.73\% (95\% CI 4.42\%-4.99\%) for Quebec, 2.88\% (95\% CI 2.75\%-3.02\%) for Ontario, 3.27\% (95\% CI 2.72\%-3.70\%) for Alberta, and 2.95\% (95\% CI 2.77\%-3.15\%) for British Columbia. Among the cohorts considered in this study, the estimated total number of infections ranged from 2-fold the number of diagnoses (among Quebecers, aged $\geq 70$ years: 26,476/53,549, 49.44\%) to 6-fold the number of diagnoses (among British Columbians aged $\geq 70$ years: $3108 / 18,147,17.12 \%$ ).

Conclusions: Our estimates indicate that a high proportion of the population infected between March 1 and November 30, 2020, remained undiagnosed. Knowledge of COVID-19 period prevalence and the undiagnosed population can provide vital evidence that policy makers can consider when planning COVID-19 control interventions and vaccination programs.

(JMIR Public Health Surveill 2021;7(9):e26409) doi: $\underline{10.2196 / 26409}$

\section{KEYWORDS}

COVID-19; prevalence; undiagnosed proportion; mathematical modeling; estimate; Canada; diagnosis; control; distribution; infectious disease; model; framework; progression; transmission

\section{Introduction}

The epidemiological information used to plan and evaluate strategies to prevent the spread of COVID-19 has undergone rapid changes since the start of the pandemic. As with many countries across the world, most Canadian provinces have enforced nonpharmaceutical interventions (NPIs) such as travel bans, school closures, and restrictions on nonessential businesses, workplaces, and social gatherings [1-4]. These measures, coupled with the highly uncertain and life-threatening nature of the disease, have resulted in profound societal and economic impacts [5].

With the high number of observed symptomless cases [3,4,6-12], there is now strong evidence that COVID-19 remains 
asymptomatic in a significant proportion of the infected population. This feature of the disease has been hypothesized to be a main driver of the rapid spread of COVID-19 worldwide $[1,2]$. Studies have also demonstrated that the transmissibility of SARS-CoV-2, the causative agent of COVID-19 via asymptomatic and symptomatic individuals is similar $[13,14]$.

With the emergence of new, more transmissible variants of SARS-CoV-2 [15] and given the age-dependence of the likelihood of transmission and hospitalization following infection [16,17], the development of a successful COVID-19 control strategy requires a thorough understanding of the trends in the geographic and demographic distribution of disease burden. Estimation of the undiagnosed population is crucial for the planning and allocation of resources needed to implement restrictions for preventing disease spread and, more importantly, for knowing when it is appropriate to relax such restrictions. In addition, knowledge of the size of the previously infected population is of importance for estimating the remaining susceptible population and for planning next-generation vaccination drives in response to emerging variants [18].

In Canada, data on COVID-19 prevalence that include the undiagnosed population are extremely limited. Estimates of prevalence of the disease have included seroprevalence studies [19-24]. These likely underestimate the true COVID-19 prevalence owing to small sample sizes and an undersampling of the groups that are most affected by COVID-19, such as lower socioeconomic status groups and immigrant groups [25,26]. Alternatively, COVID-19 prevalence and incidence can be inferred using a back-calculation approach [27,28], in which recently observed occurrences of COVID-19-related late-stage events (eg, COVID-19-related deaths) are mapped backward using a mathematical simulation model of the natural history of the disease. An important advantage of the back-calculation approach over others is its ability to include the undiagnosed population in the prevalence estimation.

Our objective is to estimate the period prevalence of COVID-19 between March 1 and November 30, 2020, and the proportion of the infected population that remained undiagnosed in the Canadian provinces of Quebec (QC), Ontario (ON), Alberta $(\mathrm{AB})$, and British Columbia (BC) by using a model-based back-calculation framework. These estimates are derived for three different age cohorts (under 30; 30-69; and $\geq 70$ years) in each of the provinces studied. These provinces are the four most populated in Canada and were selected because the vast majority of COVID-19 cases in Canada were observed in these geographic regions across the study period.

This study presents a framework for estimating the disease burden by region, demographics, and diagnosis status. A disease progression and transmission model is used to estimate the size and composition of the COVID-19 period prevalence by integrating the results of previous seroprevalence surveys with primary provincial observed data of health events related to COVID-19 and its sequelae, including COVID-19-related deaths. From these estimates, we derive the proportion of the infected population that remained undiagnosed during this period.

\section{Methods}

\section{Overview}

A mathematical framework based on a compartmental disease progression and transmission model was developed for the estimation of the period prevalence for a given population. The framework was applied to COVID-19 data from each of QC, $\mathrm{ON}, \mathrm{AB}$, and BC. For each province, a Markov chain Monte Carlo (MCMC)-based Bayesian state estimation algorithm [29] was used to construct joint posterior probability distributions for the unknown model parameters and the daily number of individuals in each COVID-19 health state. These probability distributions are constructed by iteratively comparing the model-generated mean estimates of the daily numbers of COVID-19-related health events and period prevalence against observed calibration targets. The calibration targets were obtained from provincial data collected between March 1 and November 30, 2020, that reported (1) daily cases of newly diagnosed COVID-19 [30-33], (2) daily new deaths attributed to COVID-19, and (3) COVID-19 seroprevalence [21-24]. An overview of our proposed method is presented in the following subsections. A detailed methodology section is included in Multimedia Appendix 1.

\section{Disease Progression Model Assumptions}

For each province, we develop an age-stratified "susceptible-infectious-removed" (SIR) compartmental framework to describe the progression through various disease states for individuals of the population. We stratified each population into three age cohorts: $<30,30$ to 69 , and $\geq 70$ years. The model is structured based on the COVID-19 natural history model illustrated in Figure 1. The infectious state is subdivided into 4 health states: (1) state A, representing infected individuals who show no symptoms and are undiagnosed; (2) state U, representing symptomatic and undiagnosed individuals; (3) state $\mathrm{D}$, representing individuals who are symptomatic and diagnosed; and (4) state H, representing hospitalized individuals. Individuals who recover $(\mathrm{R})$ or die $(\mathrm{X})$ are considered to be in the removal state.

We assume that individuals who reach state $\mathrm{D}$ do so by progressing through the states $\mathrm{A} \rightarrow \mathrm{U} \rightarrow \mathrm{D}$. We also assume that the daily probability of recovery of an infected individual depends on their age cohort and whether they are in state A, state $\mathrm{U}$ or $\mathrm{D}$, or state $\mathrm{H}$. We assume all deaths due to COVID-19 are diagnosed and hospitalized prior to death. We assume that COVID-19-related mortality decreases gradually over time for all age groups as a result of better understanding of the disease and that the daily probability of diagnosing a COVID-19 infection has increased gradually since the start of the pandemic as a result of improved testing capacity. 
Figure 1. COVID-19 model conceptual diagram. Health states: Susceptible (S); asymptomatic and undiagnosed (A); symptomatic and undiagnosed (U); symptomatic and diagnosed (D); hospitalized (H); recovered (R); and death (X).

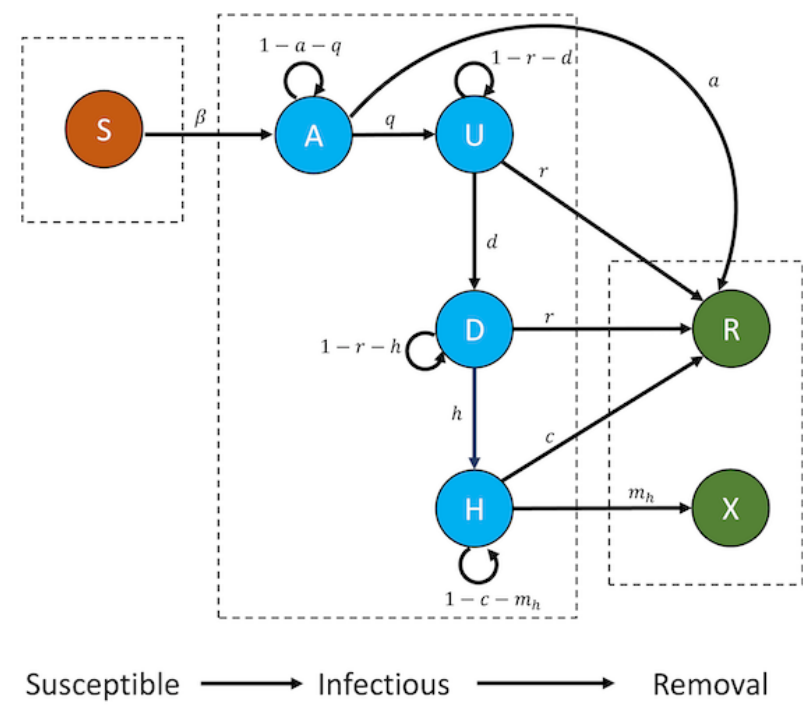

\section{Disease Transmission Dynamics Assumptions}

Within each province, we assume the disease to be transmissible across different age cohorts. We assume that the infectiveness of an infected individual will depend on whether they have been diagnosed (due to self-isolation following a diagnosis) and on whether they show symptoms [34]. Thus, the mean number of daily new infections caused by an infected individual will vary depending on their health state (A, $\mathrm{U}$, or $\mathrm{D})$.

Canadian Provinces have implemented NPIs to combat the spread of COVID-19. These interventions include travel bans, closure of schools and nonessential businesses, and limits on social gatherings. To reflect the effects of NPIs, seasonal effects on the transmissibility of SARS-CoV-2, and changes in public behavior, the infection rates $K_{A}, K_{U}$, and $K_{D}$ are allowed to vary over 9 different periods: The first three periods (March 1-11, March 12-29, and March 30 to June 1, 2020) reflect the periods of preimplementation, partial implementation, and full implementation of NPIs, respectively. The latter periods correspond to each of the months of June to November 2020. The daily probability of diagnosis of infected individuals is assumed to have increased gradually between March 1 and November 30,2020, reflecting increases in testing capacity across this period.

\section{$\beta$ - mean number of daily new infections \\ $q$ - daily probability of an asymptomatic infected individual developing symptoms}

$a-$ daily probability of recovery of an asymptomatic infected individual

$r$ - daily probability of recovery of a non-hospitalized symptomatic infected individual

$d$ - daily probability of diagnosis of an undiagnosed symptomatic infected individual

$h$ - daily probability of hospitalization of a diagnosed infected individual

$c$ - daily probability of recovery after hospitalization

$m_{h}$ - daily probability of death after hospitalization

\section{Model Fitting}

Health event data reporting the daily numbers of diagnosed cases and COVID-19-related deaths were collected for each province and age group for the study period. A summary of the cumulative diagnoses and COVID-19-related deaths as of November 30, 2020, is provided in Table 1.

Statistics on rates of recovery, testing, and hospitalization across the study period were also collected [30-33]. From these data, initial estimates of the mean values of the daily probabilities of hospitalization for diagnosed cases, as well as the daily probabilities of recovery and death for diagnosed and hospitalized cases, were calculated. Initial estimates of the mean daily probability of developing symptoms and of being discharged from the hospital were obtained from the literature [35,36]. The Metropolis-Hastings MCMC (MH-MCMC) algorithm was used to calibrate the remaining unknown parameters (Multimedia Appendix 2), and Kalman filtering was used to calibrate the daily number of individuals within each health state. The negative sum of the square of the weighted differences between (1) the expected and observed daily numbers of confirmed cases and deaths and (2) the expected and observed seroprevalence (Table 2) was used to approximate the log-likelihood function for computing the posterior distributions of unknown parameters and the unobserved daily numbers of individuals in each health state. 
Table 1. Cumulative observed COVID-19 diagnoses and deaths as per data for Quebec, Ontario, Alberta, and British Columbia as of November 30, 2020

\begin{tabular}{|c|c|c|c|}
\hline Province and age cohort (years) & Population & Cumulative diagnoses as of November 30, 2020 & Cumulative deaths as of November 30,2020 \\
\hline \multicolumn{4}{|l|}{ Quebec } \\
\hline$<30$ & $2,829,745$ & 45,778 & 4 \\
\hline $30-69$ & $4,534,110$ & 71,658 & 584 \\
\hline$\geq 70$ & $1,121,110$ & 26,476 & 6467 \\
\hline \multicolumn{4}{|l|}{ Ontario } \\
\hline$<30$ & $5,227,392$ & 38,464 & 0 \\
\hline $30-69$ & $7,607,840$ & 62,331 & 471 \\
\hline$\geq 70$ & $1,731,315$ & 15,692 & 3084 \\
\hline \multicolumn{4}{|l|}{ Alberta } \\
\hline$<30$ & $1,674,906$ & 23,207 & 3 \\
\hline $30-69$ & $2,314,614$ & 32,223 & 67 \\
\hline$\geq 70$ & 381,796 & 4013 & 491 \\
\hline \multicolumn{4}{|l|}{ British Columbia } \\
\hline$<30$ & $1,681,252$ & 12,054 & 0 \\
\hline $30-69$ & $2,747,468$ & 18,624 & 67 \\
\hline$\geq 70$ & 642,616 & 3108 & 374 \\
\hline
\end{tabular}

Table 2. Canadian provincial COVID-19 seroprevalence surveys conducted between March 2020 and July 2020 used for model fitting.

\begin{tabular}{|c|c|c|c|c|}
\hline \multirow[t]{2}{*}{ Province and survey date } & \multicolumn{3}{|l|}{ Seroprevalence } & \multirow[t]{2}{*}{ Reference } \\
\hline & Age adjusted $\%(95 \% \mathrm{CI})$ & Total assays, $\mathrm{n}$ & Positive assays, $\mathrm{n}(\%)$ & \\
\hline \multicolumn{5}{|l|}{ Quebec } \\
\hline July 9,2020 & $2.23(1.90-2.56)$ & 7691 & $173(2.25)$ & {$[22]$} \\
\hline \multicolumn{5}{|l|}{ Ontario } \\
\hline April 30, 2020 & $0.5(0.1-1.5)$ & 827 & $3(0.36)$ & {$[21]$} \\
\hline May 31,2020 & $1.5(0.7-2.2)$ & 1061 & $15(1.41)$ & {$[21]$} \\
\hline June 18,2020 & $0.96(0.810-1.113)$ & 19,839 & $189(0.95)$ & {$[23]$} \\
\hline June 30,2020 & $1.1(0.8-1.3)$ & 7014 & $79(1.12)$ & {$[21]$} \\
\hline \multicolumn{5}{|l|}{ Alberta } \\
\hline June 18,2020 & $0.37(0.182-0.552)$ & 5644 & $24(0.42)$ & {$[23]$} \\
\hline \multicolumn{5}{|l|}{ British Columbia } \\
\hline March 13, 2020 & $0.28(0.03-0.95)$ & 869 & $2(0.23)$ & {$[24]$} \\
\hline May 27, 2020 & $0.55(0.15-1.37)$ & 885 & $4(0.45)$ & {$[24]$} \\
\hline June 18, 2020 & $0.50(0.304-0.694)$ & 4962 & $29(0.58)$ & {$[23]$} \\
\hline
\end{tabular}

\section{Model Validation}

The disease progression model was used to back-calculate each cohort's COVID-19 period prevalence based on the reported confirmed cases and deaths shown in Table 1, in addition to early provincial seroprevalence results as reported in Table 2. The fitted models generally showed close agreement with these data across the four provinces and three age cohorts. Multimedia Appendix 3 shows the fit of the models to the reported daily numbers of confirmed cases and deaths.
Table 3 summarizes the seroprevalence in Ontario for the months of July and August 2020 [19,20], which was reported by Public Health Ontario to be $1.1 \%(0.8 \%-1.3 \%)$. These two latter reported seroprevalences were not used as observed data in the model fitting but were instead used to validate the fitted model. Our calibrated model for Ontario showed close agreement with these latter seroprevalence survey results, with an estimated mean period prevalence of $1.13 \%$ as of July 31 $(164,740$ cases $)$ and $1.20 \%$ (175,050 cases) as of August 31. 
Table 3. Provincial COVID-19 seroprevalence surveys between July 2020 and August 2020 used for model validation in Ontario, Canada.

\begin{tabular}{|c|c|c|c|c|}
\hline \multirow[t]{2}{*}{ Date } & \multicolumn{3}{|l|}{ Seroprevalence } & \multirow[t]{2}{*}{ Reference } \\
\hline & Age adjusted $\%(95 \% \mathrm{CI})$ & Total assays, $\mathrm{n}$ & Positive assays, $\mathrm{n}(\%)$ & \\
\hline July 31, 2020 & $1.1(0.8-1.3)$ & 7001 & $70(0.99)$ & {$[20]$} \\
\hline August 31,2020 & $1.1(0.8-1.3)$ & 6789 & $72(1.06)$ & [19] \\
\hline
\end{tabular}

\section{Results}

\section{Prevalence and Total Incidence Estimates}

The mean estimates of the COVID-19 period prevalence between March 1 and November 30, 2020, for each province are as follows: $4.73 \%$ (95\% CI $4.42 \%-4.99 \%)$ for QC, $2.88 \%$ (95\% CI $2.75 \%-3.02 \%)$ for ON; 3.27\% (95\% CI 2.72\%-3.70\%) for $\mathrm{AB}$; and $2.95 \%$ (95\% CI $2.77 \%-3.15 \%)$ for $\mathrm{BC}$, as illustrated in Figure 2.

Figure 3 shows the observed and estimated cumulative total number of infections for each age cohort up to November 30, 2020. For that date, the median estimates of the cumulative total numbers of infected individuals were as follows: 135,407 (95\% CI 126,380-143,185) for QC, 151,443 (95\% CI $144,707-158,804)$ for ON, 55,596 (95\% CI 45,892-63,063) for
$\mathrm{AB}$, and 50,356 (95\% CI 47,318-53,912) for BC, among individuals aged under 30 years; $212,048 \quad(95 \%$ CI $198,212-223,863)$ for QC, 218,446 (95\% CI 208,519-228,609) for ON, 75,246 (95\% CI 62,932-85,136) for AB, 80,915 (95\% CI 76,063-86,605) for BC, among individuals aged between 30 and 69 years; and 53,549 (95\% CI 50,462-56,298) for QC, 49,937 (95\% CI 47,614-52,440) for ON, 11,932 (95\% CI 9,961-13,445) for AB, 18,147 (95\% CI 17,076-19,397) for BC, among individuals aged 70 years or above. Multimedia Appendix 4 shows the estimated distributions of the cumulative total number of individuals with COVID-19 infection and the reported cumulative total number of individuals diagnosed with COVID-19 infection. Summary statistics for the distributions are tabulated in Multimedia Appendix 5. These estimates include both the diagnosed and undiagnosed populations and they range between 2 and 6 times the reported diagnoses of the provinces as, illustrated in Figure 3.

Figure 2. Estimated COVID-19 period prevalence in Quebec, Ontario, Alberta, and British Columbia between March 1 and November $30,2020$. 
Figure 3. Estimated trajectories of cumulative total COVID-19 cases, cumulative reported COVID-19 diagnoses, and cumulative reported COVID-19 deaths in Quebec, Ontario, Alberta, and British Columbia between March 1 and November 30, 2020. CB: credible band.

\section{Age $<30$}
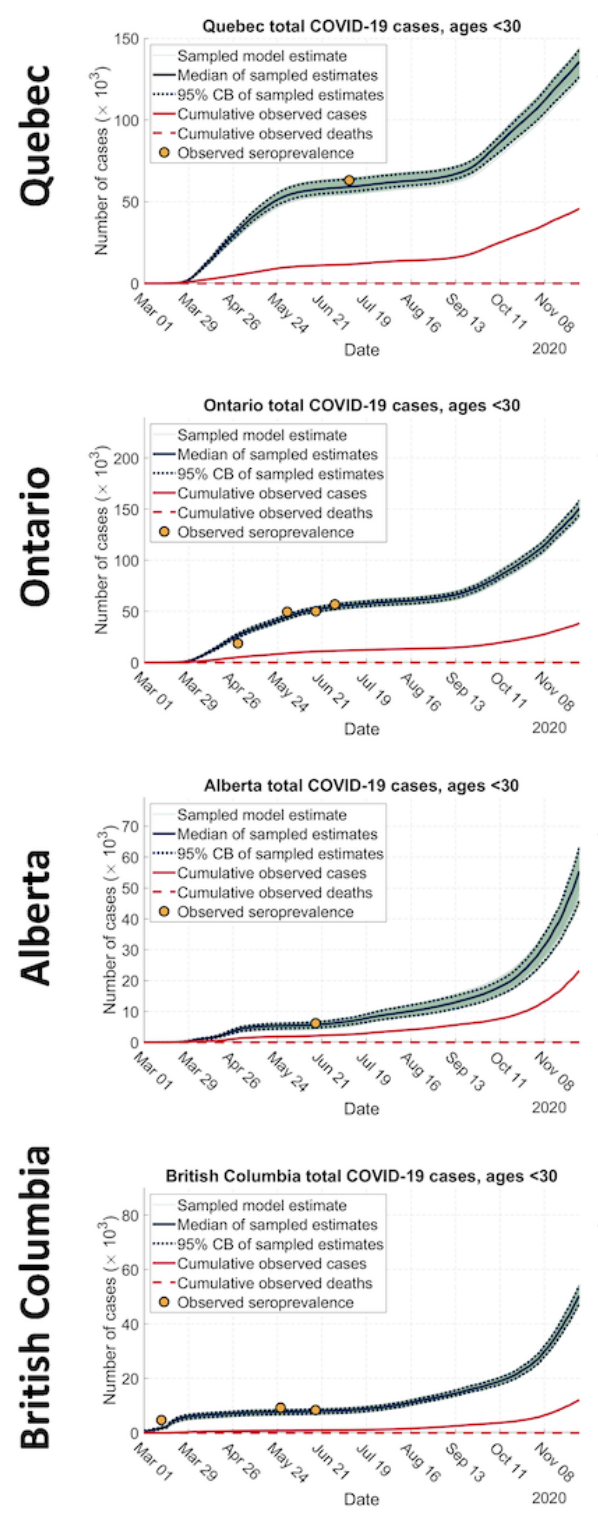

\section{Undiagnosed Proportion}

Across the study period, the estimated proportion of the total infected population that was undiagnosed in each cohort and province was as follows: $66.19 \%$ (95\% CI $63.78 \%-68.03 \%)$ for QC, $74.60 \%$ (95\% CI 73.42\%-75.78\%) for ON, $58.26 \%(95 \%$ CI $49.43 \%-63.20 \%)$ for $\mathrm{AB}$, and $76.06 \% \quad(95 \% \quad \mathrm{CI}$ $74.53 \%-77.64 \%)$ for $\mathrm{BC}$ among individuals under 30 years; $66.21 \%$ (95\% CI $63.85 \%-67.99 \%$ ) for QC, $71.47 \%(95 \%$ CI $70.11 \%-72.73 \%$ ) for ON, $57.18 \%$ (95\% CI 48.80\%-62.15\%) for $\mathrm{AB}$, and $76.98 \%$ (95\% CI 75.52\%-78.50\%) for BC among individuals aged between 30 and 69 years; and $50.56 \%(95 \%$ CI 47.53\%-52.97\%) for QC, 68.58\% (95\% CI 67.04\%-70.08\%) for ON, $66.37 \%$ (95\% CI 59.71\%-70.15\%) for $\mathrm{AB}$, and $82.87 \%$ (95\% CI $81.80 \%-83.98 \%$ ) for BC among individuals aged 70 years and above.
Age 30-69
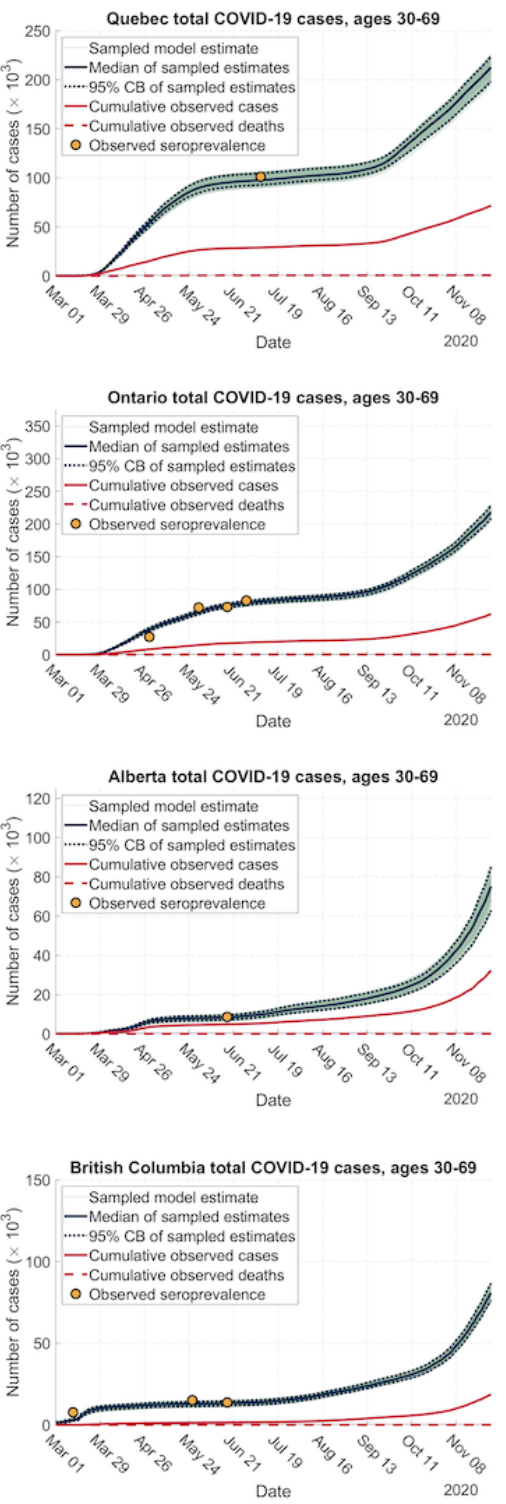

Age $70+$
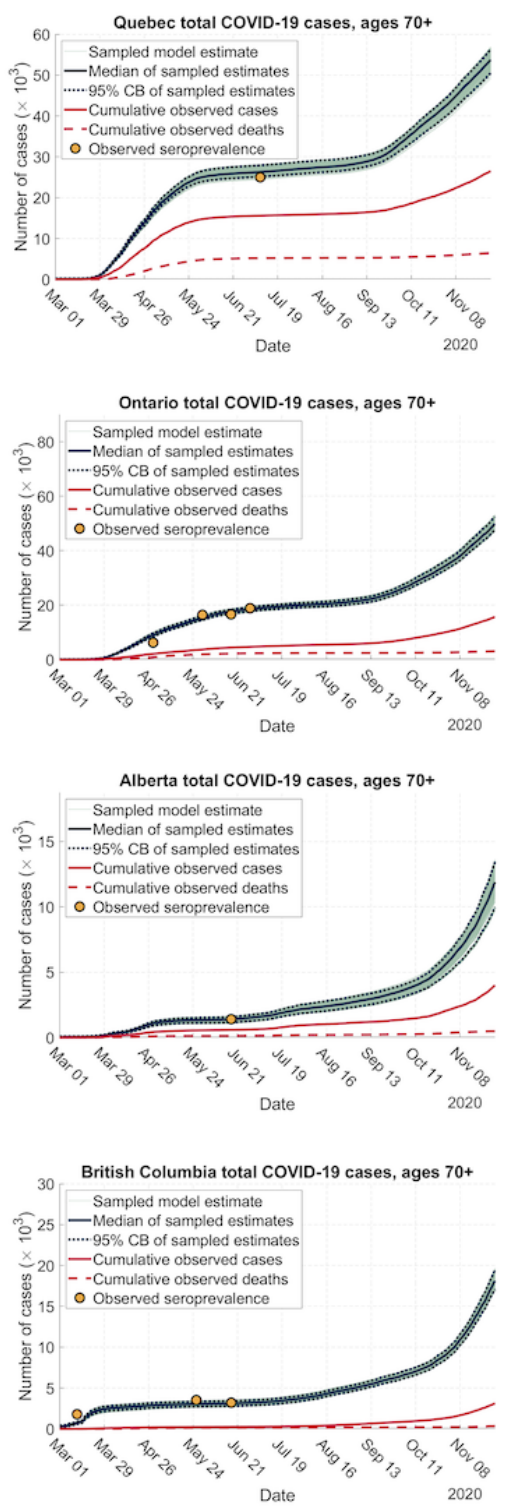

\section{Principal Findings}

We have combined our mathematical model with detailed province-level data to provide a comprehensive and robust estimate of the burden of COVID-19 infections in four large Canadian provinces between March 1 and November 30, 2020. Across all provinces and cohorts studied, our model-based prevalence estimates indicate that the period prevalence from March 1 to November 30, 2020, including both the diagnosed and undiagnosed populations, ranged between 2- to 6-fold the reported diagnosed period prevalence.

A variety of methods have previously been used to estimate the true prevalence of infectious diseases in Canada and around the world, including that of hepatitis C and HIV [37-41]. Common methods include seroprevalence surveys and model-based 
approaches [39]. Our findings suggest that the prevalence of COVID-19 in Canada over the study period was significantly higher than estimates based on data reported by provinces. In comparison, our estimates are congruent with seroprevalence surveys [3,4,6,42,43] and model-based approaches [27,28] conducted elsewhere around the world. Specifically, Bajema et al [42] reported the results of a large-scale seroprevalence survey conducted in the United States and found that the seroprevalence of New York state can be as high as $23 \%$, much higher than the reported cases. Rostami et al [43] reported a systematic review and meta-analysis of seroprevalence of 23 countries worldwide and concluded that over 263 million people had been exposed or infected with COVID-19 as of the end of August 2020, roughly 10 times more than the 25 million people reported [44]. Flaxman et al [27] generated a model-based prevalence estimate based on a back-calculation method for 11 European countries and concluded that there are considerably fewer COVID-19 cases detected than their model estimated due to the presence of asymptomatic or mild cases. Perkins et al [28] also used a mathematical modeling approach to estimate the unobserved incidence in the United States and reported that the number of detected symptomatic infections was less than $10 \%$ of the total infected population during the early stage of the pandemic. As testing capacity has increased over time, the daily probability of diagnosis of a given infected individual will also have increased. Consequently, it is to be expected that the ratio between the overall prevalence and estimates of prevalence based solely on diagnosis figures will be lower than what has been reported for earlier stages of the pandemic. Our 2- to 6-fold estimates reasonably reflect this fact.

In contrast to the cross-sectional "snapshots" of the pandemic offered by seroprevalence surveys, our model-based approach provides longitudinal estimates of the COVID-19 population, which unveils the trends in the true spread of the disease over time as well as insights into the medium- to long-term effectiveness of NPIs in limiting transmissions. On the other hand, our analysis is subject to certain limitations. First, accurately estimating the period prevalence depends on knowledge of key model parameters such as the transmission rates and probabilities of diagnosis. The initial values of these parameters that were used in our model may have inherited biases from the existing literature on the natural history of COVID-19. However, through the Bayesian approach, uncertainties in these parameters are ultimately reflected in the credible intervals of the final prevalence estimates. Second, our method can, in principle, be applied to Canadian regions not considered in this study as well as to other countries. However, our longitudinal estimates of the period prevalence require high-resolution time-series data on the number of confirmed cases and deaths in each region and age cohort under investigation.

Establishing a robust baseline estimate of the prevalence and undiagnosed proportion is critical, as it contains important information for decision makers to plan for the future regarding how many individuals are likely to require vaccination and how much extra screening effort is needed to diagnose unaware infected individuals to prevent transmission. Our study provided estimates from the period of March 1 to November 30, 2020. Towards the end of the study period, COVID-19 vaccines were on track for deployment around the globe [45]. In recent months, these vaccines have been proven to be highly effective [46]. At the same time, new SARS-CoV-2 variants have reversed downward trends in infections even in countries with good rates of vaccination coverage [15], where these rapidly changing circumstances have prompted a re-evaluation of plans to ease NPIs. Given the higher transmissibility of the novel SARS-CoV-2 variants, updated estimates of the prevalence and undiagnosed proportion will be necessary, as this information contains important indicators for decision-makers to plan for future interventions, such as the distribution of next-generation vaccines [18].

If testing costs and time continue to decrease, expanding the number of tests can increase the diagnosis rate and reduce potential asymptomatic transmission [47]. However, to determine the appropriate level of expansion, such as, for example, whether to target specific high-risk populations or to conduct a general population screening, a cost-effectiveness analysis and budget impact analysis would be required [48]. Our framework for the inference of COVID-19 prevalence would provide pivotal parameters and estimates for these analyses.

\section{Conclusions}

Our study provides a framework for estimating the prevalence of COVID-19 in Canada and indicates a substantial proportion of the population infected between March 1 and November 30, 2020 , remained undiagnosed. The analysis we have presented provides a more complete picture of the pandemic than would be indicated from observations that only focus on COVID-19 diagnosis statistics. This information is critical for policy makers and public health officials when considering the implementation or relaxation of interventions for controlling COVID-19.

\section{Acknowledgments}

This work was partially supported by an Ontario Ministry of Research, Innovation, and Science Early Researcher Award that was awarded to WW. This work was also partially supported by Discovery Grants from the Natural Sciences and Engineering Research Council of Canada (NSERC) (1257369 to WW and 400095 to ZF).

\section{Conflicts of Interest}

None declared. 


\section{Multimedia Appendix 1}

Detailed methodology section.

[DOCX File, 79 KB-Multimedia Appendix 1]

\section{Multimedia Appendix 2}

Model parameters and their Bayesian estimates.

[DOCX File, 72 KB-Multimedia Appendix 2]

\section{Multimedia Appendix 3}

Model validation results.

[DOCX File, 1259 KB-Multimedia Appendix 3]

\section{Multimedia Appendix 4}

Distribution of the estimated cumulative total number of COVID-19 cases, reported cumulative diagnoses, and reported cumulative deaths.

[DOCX File, 494 KB-Multimedia Appendix 4]

\section{Multimedia Appendix 5}

Estimated cumulative total COVID-19 infections as of November 30, 2020.

[DOCX File , 44 KB-Multimedia Appendix 5]

\section{References}

1. Peeri NC, Shrestha N, Rahman MS, Zaki R, Tan Z, Bibi S, et al. The SARS, MERS and novel coronavirus (COVID-19) epidemics, the newest and biggest global health threats: what lessons have we learned? Int J Epidemiol 2020 Feb 22:717-726. [doi: 10.1093/ije/dyaa033] [Medline: $\underline{\text { 32086938] }}$

2. Zhao H, Lu X, Deng Y, Tang Y, Lu J. COVID-19: asymptomatic carrier transmission is an underestimated problem. Epidemiol. Infect 2020 Jun 11;148:E116. [doi: 10.1017/s0950268820001235]

3. Sood N, Simon P, Ebner P, Eichner D, Reynolds J, Bendavid E, et al. Seroprevalence of SARS-CoV-2-Specific Antibodies Among Adults in Los Angeles County, California, on April 10-11, 2020. JAMA 2020 Jun 16;323(23):2425-2427 [FREE Full text] [doi: 10.1001/jama.2020.8279] [Medline: 32421144]

4. Goodman D, Rothfeld M. 1 in 5 New Yorkers May Have Had Covid-19, Antibody Tests Suggest. The New York Times. 2020. URL: https://www.nytimes.com/2020/04/23/nyregion/coronavirus-antibodies-test-ny.html [accessed 2021-08-31]

5. Antunes P, Stewart M. Economic Implications of Social Distancing to August. The Conference Board of Canada. 2020 Mar 23. URL: https://www.conferenceboard.ca/research/economic-implications-of-social-distancing?AspxAuto DetectCookieSupport=1 [accessed 2021-08-31]

6. Baggett TP, Keyes H, Sporn N, Gaeta JM. Prevalence of SARS-CoV-2 infection in residents of a large homeless shelter in Boston. JAMA 2020 Jul 02;323(21):2191-2192 [FREE Full text] [doi: 10.1001/jama.2020.6887] [Medline: 32338732]

7. Wong J, Abdul Aziz ABZ, Chaw L, Mahamud A, Griffith MM, Lo Y, et al. High proportion of asymptomatic and presymptomatic COVID-19 infections in air passengers to Brunei. J Travel Med 2020 Aug 20;27(5):taaa066 [FREE Full text] [doi: 10.1093/jtm/taaa066] [Medline: $\underline{32365178}$ ]

8. Hijnen D, Marzano AV, Eyerich K, GeurtsvanKessel C, Giménez-Arnau AM, Joly P, et al. SARS-CoV-2 transmission from presymptomatic meeting attendee, Germany. Emerg Infect Dis 2020 Aug;26(8):1935-1937 [FREE Full text] [doi: 10.3201/eid2608.201235] [Medline: $\underline{\text { 32392125] }}$

9. Dong Y, Mo X, Hu Y, Qi X, Jiang F, Jiang Z, et al. Epidemiology of COVID-19 among children in China. Pediatrics 2020 Jun;145(6):e20200702 [FREE Full text] [doi: 10.1542/peds.2020-0702] [Medline: 32179660]

10. Yanes-Lane M, Winters N, Fregonese F, Bastos M, Perlman-Arrow S, Campbell JR, et al. Proportion of asymptomatic infection among COVID-19 positive persons and their transmission potential: A systematic review and meta-analysis. PLoS One 2020;15(11):e0241536 [FREE Full text] [doi: 10.1371/journal.pone.0241536] [Medline: $\underline{33141862]}$

11. Al-Sadeq DW, Nasrallah GK. The incidence of the novel coronavirus SARS-CoV-2 among asymptomatic patients: A systematic review. Int J Infect Dis 2020 Oct;98:372-380 [FREE Full text] [doi: 10.1016/j.ijid.2020.06.098] [Medline: $\underline{32623083}$ ]

12. He J, Guo Y, Mao R, Zhang J. Proportion of asymptomatic coronavirus disease 2019: A systematic review and meta-analysis. J Med Virol 2021 Feb;93(2):820-830 [FREE Full text] [doi: 10.1002/jmv.26326] [Medline: 32691881]

13. He D, Zhao S, Lin Q, Zhuang Z, Cao P, Wang MH, et al. The relative transmissibility of asymptomatic COVID-19 infections among close contacts. Int J Infect Dis 2020 May;94:145-147 [FREE Full text] [doi: 10.1016/j.ijid.2020.04.034] [Medline: $\underline{32315808]}$ 
14. Yin G, Jin H. Comparison of transmissibility of coronavirus between symptomatic and asymptomatic patients: reanalysis of the Ningbo COVID-19 data. JMIR Public Health Surveill 2020 May 28;6(2):e19464 [FREE Full text] [doi: 10.2196/19464] [Medline: 32442131]

15. Mahase E. Delta variant: What is happening with transmission, hospital admissions, and restrictions? BMJ 2021 Jul 15;373:n1513. [doi: 10.1136/bmj.n1513] [Medline: 34130949]

16. Mueller AL, McNamara MS, Sinclair DA. Why does COVID-19 disproportionately affect older people? Aging (Albany NY) 2020 May 29;12(10):9959-9981 [FREE Full text] [doi: 10.18632/aging.103344] [Medline: 32470948]

17. Davies NG, Klepac P, Liu Y, Prem K, Jit M, CMMID COVID-19 working group, et al. Age-dependent effects in the transmission and control of COVID-19 epidemics. Nat Med 2020 Aug;26(8):1205-1211. [doi: 10.1038/s41591-020-0962-9] [Medline: 32546824]

18. Abdool Karim SS, de Oliveira T. New SARS-CoV-2 variants - clinical, public health, and vaccine implications. N Engl J Med 2021 May 13;384(19):1866-1868. [doi: 10.1056/nejmc2100362]

19. COVID-19 Seroprevalence in Ontario: August 1 to August 31, 2020. Public Health Ontari0 - COVID-19 Serosurveillance Summary. URL: https://www.publichealthontario.ca/-/media/documents/ncov/epi/2020/10/covid-19-episeroprevalence-in-ontario-aug-31.pdf [accessed 2020-11-01]

20. COVID-19 Seroprevalence in Ontario: July 4 to July 31, 202. Public Health Ontario - COVID-19 Serosurveillance Summary. URL: https://www.publichealthontario.ca/-/media/documents/ncov/epi/2020/10/covid-19-episeroprevalence-in-ontario-july-31.pdf [accessed 2020-11-01]

21. COVID-19 Seroprevalence in Ontario: March 27, 2020 to June 30, 2020. Public Health Ontario - COVID-19 Serosurveillance Summary. URL: https://www.publichealthontario.ca/-/media/documents/ncov/epi/2020/07/covid-19-episeroprevalence-in-ontario.pdf?la=en [accessed 2020-11-01]

22. Étude de séroprévalence des anti-SRAS-COV-2 chez les donneurs de sang d'Héma-Québec, vers la fin de la première vague de COVID-19 - Étude no. ET-20-004, Projet COVID-20-02. Webpage in French. 2021 Jan 21. URL: https://www. hema-quebec.qc.ca/userfiles/file/coronavirus/COVID-20-02-rappot-final-20-02-2021.pdf [accessed 2021-08-31]

23. COVID-19 Seroprevalence Report - August 19, 2020. Canadian Blood Services. URL: https://www.blood.ca/sites/default/ files/CBS COVID-19 Seroprevalence Public Report Aug272020.pdf [accessed 2020-11-01]

24. Skowronski D, Sekirov I, Sabaiduc S, Zou M, Morshed M, Lawrence D. Low SARS-CoV-2 sero-prevalence based on anonymized residual sero-survey before and after first wave measures in British Columbia, Canada, March-May 2020. medRxiv. Preprint posted online on July 15, 2020. [doi: 10.1101/2020.07.13.20153148]

25. $\mathrm{Ng}$ E. COVID-19 deaths among immigrants: Evidence from the early months of the pandemic. Statistics Canada. 2021 Jun 9. URL: https://www150.statcan.gc.ca/n1/pub/45-28-0001/2021001/article/00017-eng.htm [accessed 2021-06-15]

26. Clouston SA, Natale G, Link BG. Socioeconomic inequalities in the spread of coronavirus-19 in the United States: A examination of the emergence of social inequalities. Soc Sci Med 2021 Jan;268:113554 [FREE Full text] [doi: 10.1016/j.socscimed.2020.113554] [Medline: 33308911]

27. Flaxman S, Mishra S, Gandy A, Unwin HJT, Mellan TA, Coupland H, Imperial College COVID-19 Response Team, et al. Estimating the effects of non-pharmaceutical interventions on COVID-19 in Europe. Nature 2020 Aug;584(7820):257-261. [doi: 10.1038/s41586-020-2405-7] [Medline: 32512579]

28. Perkins TA, Cavany SM, Moore SM, Oidtman RJ, Lerch A, Poterek M. Estimating unobserved SARS-CoV-2 infections in the United States. Proc Natl Acad Sci U S A 2020 Sep 08;117(36):22597-22602 [FREE Full text] [doi: 10.1073/pnas.2005476117] [Medline: 32826332]

29. Zarchan P, Musoff H. Fundamentals of Kalman Filtering: A Practical Approach, Fourth Edition. Reston, Virginia: American Institute of Aeronautics and Astronautics; Jan 2015.

30. COVID-19 vaccinations data. Government of Ontario. URL: https://covid-19.ontario.ca/data [accessed 2020-07-02]

31. Data on COVID-19 in Québec. Québec.ca - Official website of the Gouvernement du Québec. 2020 Jul 02. URL: https:/ /www.quebec.ca/en/health/health-issues/a-z/2019-coronavirus/situation-coronavirus-in-quebec/ [accessed 2021-08-31]

32. BC COVID-19 Data. BC Center for Disease Control. URL: http://bccdc.ca/covid19data [accessed 2020-07-02]

33. COVID-19 Alberta Statistics. Government of Alberta. URL: https://covid19stats.alberta.ca [accessed 2020-07-02]

34. He X, Lau EHY, Wu P, Deng X, Wang J, Hao X, et al. Temporal dynamics in viral shedding and transmissibility of COVID-19. Nat Med 2020 May 15;26(5):672-675. [doi: 10.1038/s41591-020-0869-5] [Medline: $\underline{\text { 32296168] }}$

35. Lauer SA, Grantz KH, Bi Q, Jones FK, Zheng Q, Meredith HR, et al. The incubation period of coronavirus disease 2019 (COVID-19) from publicly reported confirmed cases: estimation and application. Ann Intern Med 2020 May 05;172(9):577-582 [FREE Full text] [doi: 10.7326/M20-0504] [Medline: 32150748]

36. Li L, Huang T, Wang Y, Wang Z, Liang Y, Huang T, et al. COVID-19 patients' clinical characteristics, discharge rate, and fatality rate of meta-analysis. J Med Virol 2020 Jun 23;92(6):577-583 [FREE Full text] [doi: 10.1002/jmv.25757] [Medline: 32162702]

37. Sweeting MJ, De Angelis D, Brant LJ, Harris HE, Mann AG, Ramsay ME. The burden of hepatitis C in England. J Viral Hepat 2007 Aug;14(8):570-576. [doi: 10.1111/j.1365-2893.2007.00851.x] [Medline: 17650291]

38. Deuffic-Burban S, Mathurin P, Valleron A. Modelling the past, current and future HCV burden in France: detailed analysis and perspectives. Stat Methods Med Res 2009 Jul 26;18(3):233-252. [doi: 10.1177/0962280208094697] [Medline: 19036916] 
39. Hamadeh A, Feng Z, Krahn M, Wong WWL. A model-based framework for chronic hepatitis C prevalence estimation. PLoS One 2019 Nov 21;14(11):e0225366 [FREE Full text] [doi: 10.1371/journal.pone.0225366] [Medline: 31751393 ]

40. Trubnikov M, Yan P, Archibald C. Estimated prevalence of Hepatitis C Virus infection in Canada, 2011. Can Commun Dis Rep 2014 Dec 18;40(19):429-436 [FREE Full text] [doi: 10.14745/ccdr.v40i19a02] [Medline: 29769874]

41. Rosenberg PS, Biggar RJ, Goedert JJ, Gail MH. Backcalculation of the number with human immunodeficiency virus infection in the United States. Am J Epidemiol 1991 Mar 01;133(3):276-285. [doi: 10.1093/oxfordjournals.aje.a115872] [Medline: 2000845]

42. Bajema KL, Wiegand RE, Cuffe K, Patel SV, Iachan R, Lim T, et al. Estimated SARS-CoV-2 seroprevalence in the US as of September 2020. JAMA Intern Med 2021 Apr 01;181(4):450-460 [FREE Full text] [doi: 10.1001/jamainternmed.2020.7976] [Medline: 33231628]

43. Rostami A, Sepidarkish M, Leeflang MM, Riahi SM, Nourollahpour Shiadeh M, Esfandyari S, et al. SARS-CoV-2 seroprevalence worldwide: a systematic review and meta-analysis. Clin Microbiol Infect 2021 Mar;27(3):331-340 [FREE Full text] [doi: 10.1016/j.cmi.2020.10.020] [Medline: 33228974]

44. Dong E, Du H, Gardner L. An interactive web-based dashboard to track COVID-19 in real time. Lancet Infect Dis 2020 May;20(5):533-534 [FREE Full text] [doi: 10.1016/S1473-3099(20)30120-1] [Medline: 32087114]

45. Mahase E. Covid-19: Pfizer and BioNTech submit vaccine for US authorisation. BMJ 2020 Nov 20;371:m4552. [doi: 10.1136/bmj.m4552] [Medline: $\underline{33219049]}$

46. Iacobucci G. Covid-19: Two doses of Pfizer vaccine are "highly effective" against infection, hospital admission, and death, study finds. BMJ 2021 May 05;373:n1164. [doi: 10.1136/bmj.n1164] [Medline: 33952443]

47. Overview of Testing for SARS-CoV-2 (COVID-19). Centers for Disease Control and Prevention. URL: https://www. cdc.gov/coronavirus/2019-ncov/php/open-america/expanded-screening-testing.html [accessed 2021-08-31]

48. Appleby J. Tackling covid-19: are the costs worth the benefits? BMJ 2020 May 21;369:m1496. [doi: 10.1136/bmj.m1496] [Medline: $\underline{32317272]}$

\author{
Abbreviations \\ AB: Alberta \\ BC: British Columbia \\ MCMC: Markov chain Monte Carlo \\ MH-MCMC: Metropolis-Hastings Markov chain Monte Carlo \\ NPIs: nonpharmaceutical interventions \\ ON: Ontario \\ QC: Quebec \\ SIR: susceptible-infectious-removed
}

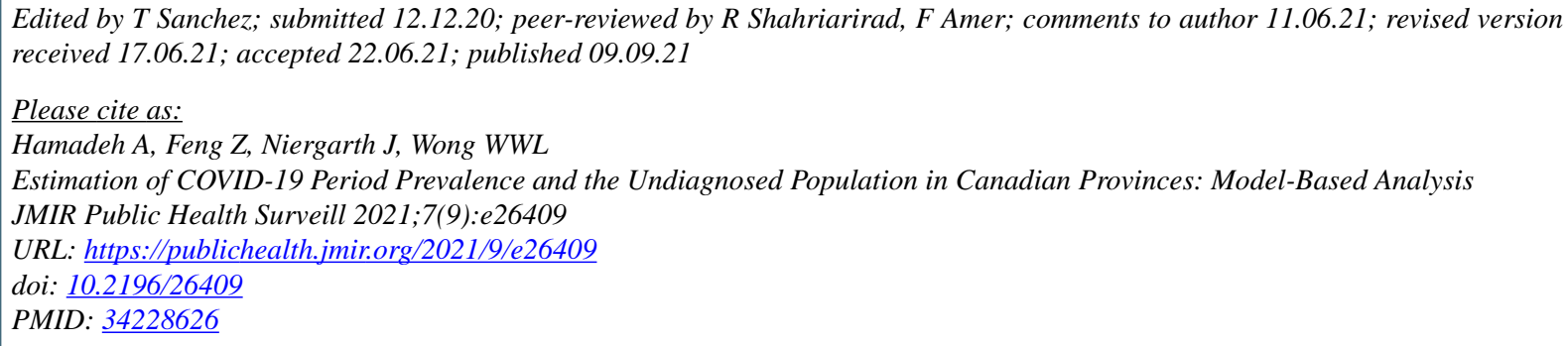

(C)Abdullah Hamadeh, Zeny Feng, Jessmyn Niergarth, William WL Wong. Originally published in JMIR Public Health and Surveillance (https://publichealth.jmir.org), 09.09.2021. This is an open-access article distributed under the terms of the Creative Commons Attribution License (https://creativecommons.org/licenses/by/4.0/), which permits unrestricted use, distribution, and reproduction in any medium, provided the original work, first published in JMIR Public Health and Surveillance, is properly cited. The complete bibliographic information, a link to the original publication on https://publichealth.jmir.org, as well as this copyright and license information must be included. 